\title{
Apple Peel Small Bowel, A Review of Four Cases: Surgical and Radiographic Aspects
}

\author{
Akinola RA ${ }^{1}$, Osuoji $\mathbf{R I}^{2}$ \\ ${ }^{1}$ Dr. RA Akinola, Department of Radiology, ${ }^{2} \mathrm{Dr}$. RL Osuoji, Department of Surgery, Paediatric Surgery unit, Both from \\ Lagos State University Teaching Hospital (LASUTH)/College of medicine, Lagos State University (LASUCOM), Ikeja, \\ Lagos. Nigeria.
}

Address for correspondence: Dr. RA Akinola, E-mail: adeyanjuakinola@yahoo.com

\begin{abstract}
Background: Although apple peel intestinal atresia is rare and is associated with a high mortality and morbidity, there is a dearth of its report in African literature. This study reviews four of the cases seen in a state teaching hospital in Lagos, considering the radiographic findings, surgical management and outcome. A brief review of literature is also undertaken. Aims and Objectives: To correle the plain radiographic findings with the surgical findings of neonates gathered over a six year period and to evaluate their surgical management, hoping to further help improve management of such neonates' in future in resource limited regions such as ours. Methodology: It was a retrospective case series of four neonates who were brought in over a period of six years and operated after an initial plain abdominal $\mathrm{X}$-ray. They were done as emergency cases, consent was obtained from their parents and the study was approved by the research and ethics committee. Operative findings were subsequently correlated with their radiographic findings and the surgical outcomes and follow up were documented. Conclusion: This study revealed that "the triple bubble sign" is a common radiographic finding in Apple Peel deformities, as well as gangrene of the jejunum and ileum at surgery.
\end{abstract}

Key words: Apple peel atresia, Jejunoileal atresia, Plain Abdominal Radiography, Parenteral nutrition, Short Bowel Syndrome.

\section{Introduction}

Apple peel atresia is a term used to describe a group of patients with a well-defined variant of high jejunal atresia near the ligament of Triez ${ }^{1}$. This term was first used by Santulli and Blanc in 1961'. It is also called Christmas tree deformity with an intestinal atresia type IIIb where both intestinal segments are separated, the bowel is foreshortened and the mesenteric defect is large ${ }^{2-9}$. The bowel distal to the atresia is precariously supplied in a retrograde fashion by anastomotic arcades from the right ileocolic or inferior mesenteric artery ${ }^{2-7,10}$. Neonates with this distinct variant of atresia tend to have a familial pattern, are often of low birth weight and frequently have a number of associated anomalies ${ }^{7,9}$.

Jejunoileal atresias and stenoses are major causes of neonatal intestinal obstruction, accounting for $95 \%$ of obstructions ${ }^{2,11}$ and intestinal atresia is said to be the second most common cause of neonatal intestinal obstruction (after anorectal malformation) in Jos, Nigeria $^{11}$. Its prevalence varies widely, from 1.3 cases per 10,000 in Spain and Latin America to 2.25 cases per 10,000 births in France ${ }^{2}$. One study in France however found an increased prevalence of intestinal atresia in infants born to teenagers ${ }^{2}$. It can occur anywhere along the gastrointestinal tract, and the anatomic location of the obstruction determines the clinical presentation.

Patients with intestinal atresia are usually of young gestational age and low birth weight, the atresia is associated with twinning, the parents are more often consanguineous when compared to parents of healthy neonates and the pregnancies are frequently associated with vaginal bleeding ${ }^{2}$. Some maternal infections may be associated with ileal atresia². 
Diagnosis of a gastrointestinal tract anomaly in the neonate or infant relies mainly on clinical findings. Most newborns with intestinal obstruction present with bilious vomiting which in the neonate should be considered secondary to a mechanical obstruction until proven otherwise ${ }^{2}$. Emergency surgical evaluation is required in every newborn with this symptom ${ }^{2}$. The role of diagnostic imaging is to help determine as accurately as possible the exact nature of the abnormality.

Intestinal obstructions in the neonate are high or low; complete or incomplete. These distinctions are critical and can almost always be made with abdominal radiography ${ }^{10}$. Neonates with complete high intestinal obstruction do not usually require further radiologic evaluation after a plain abdominal x-ray. Neonates with complete low intestinal obstruction should however undergo a contrast enema examination, which may be both diagnostic and therapeutic ${ }^{10}$. An upper gastrointestinal series must be performed in patients with incomplete high or low intestinal obstruction regardless of age to try to determine the cause of the obstruction because management is different in each case ${ }^{10}$.

Radiography is the most valuable means of determining if the obstruction is present and it is often diagnostic. Even if it is not, however, it may help determine the next most useful diagnostic procedure. Such abnormalities must be corrected surgically if the patient is to survive ${ }^{10}$. The survival of patients with intestinal obstruction has markedly improved over the last 20 years because of an improved understanding of intestinal physiology and the etiologic factors of the condition, refinements in pediatric anesthesia, and advances in surgical and perioperative care of newborns ${ }^{2,12}$

Some of the neonates may do well after surgery but some require prolonged parenteral nutritional support, some develop malabsorption syndrome while some need additional surgery to manage the resultant distension and short bowel ${ }^{13}$. Mortality from intestinal atresia is however still high in our environment ${ }^{11}$, although it is said to be reducing in the developed world ${ }^{10,12,14}$.

This study therefore aims at reviewing the cases of apple peel atresia, a rare variant of jejunoileal atresia seen in our institution over a period of six years, looking at its radiographic, operative procedures and its surgical outcomes.

\section{Materials and methods}

Four cases of apple peel atresia seen in the Lagos
State University Teaching Hospital from 2005 to 2011 were analysed in this retrospective study. They were all neonates born to mothers who were between 2228years. They presented with symptoms suggesting intestinal obstruction and a preoperative plain supine and or erect abdominal X-ray was done using a Vision, Villa Systemi X-ray machine. Consent was obtained from all the parents and approval was sought from the research and ethics committee of the hospital. They were then worked up for emergency exploratory laparotomy giving intravenous (IV) antibiotics, nasogastric tubes were introduced and they were catheterized to monitor their urinary output.

The bulbous proximal bowel segment was excised, preserving as much proximal bowel as possible. The distal deformity was excised leaving some length of intestine from the ileocaecal junction. We used an end to side or end to back anastomosis to establish continuity of the bowel. The babies were placed on IV fluids and antibiotics. Patients were followed up at outpatients clinic to exclude complications.

\section{Case 1}

A four day old premature female neonate admitted on the account of abdominal distension, nonbilious vomiting and low grade fever was delivered by spontaneous vertex delivery at 34 weeks gestation. She passed meconium immediately after birth. She had a good suckling reflex and normal bowel motions. A plain abdominal $x$-ray revealed grossly dilated stomach and bowel in the abdomen extending to both flanks and the pelvis (forming 3 bubbles of air, suggesting a "triple bubble" appearance), Fig $1 \mathrm{a}$.

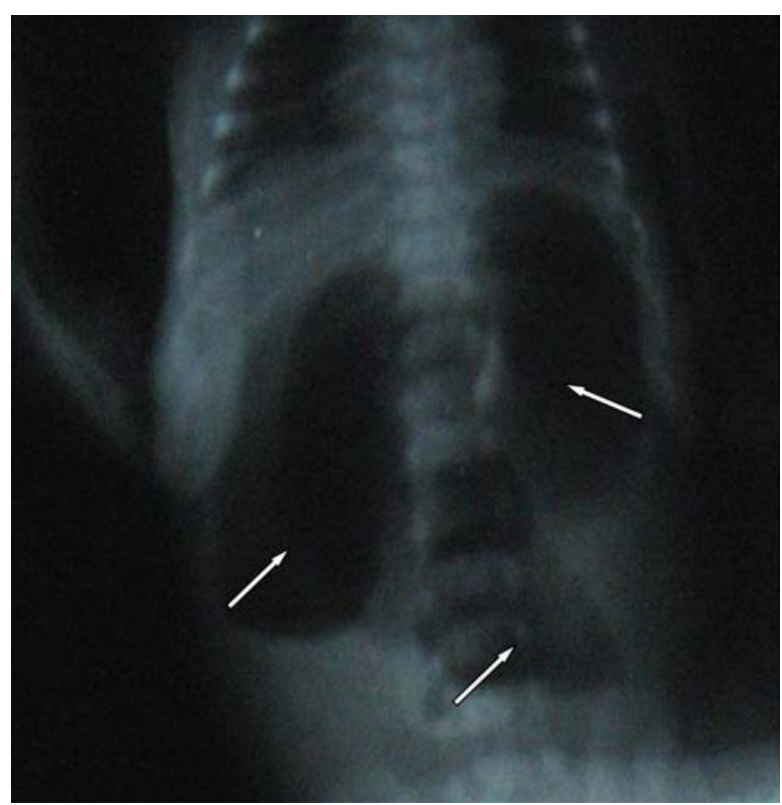

Fig 1a: Supine plain abdominal x-ray showing the triple bubble appearance 


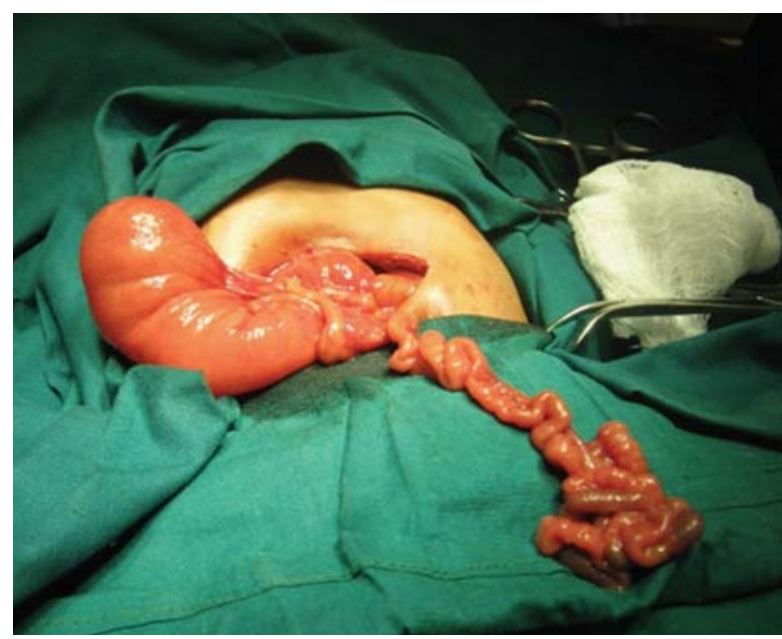

Fig 1b: Surgical finding of a dialated duodenum and proximal jejunum, absent mesentery and atretic and gangrenous ileum.

The baby was then worked up for surgery. A nasogastric tube (NG tube) was introduced, IV fluid was set up and baby was catheterized to monitor urinary output. Exploratory laparotomy revealed an Apple peel deformity of the ileum with coexisting volvulus with an atretic and gangrenous distal ileum, (Fig 1b). She had an end to back jejunoileal anastomosis and $4 \mathrm{~cm}$ of terminal ileum was preserved.

Patient was stable from the $2^{\text {nd }}-7^{\text {th }}$ day postoperative (DPO) and commenced on oral sips of $50 \mathrm{mls}$ of glucose 2 hourly on the $8^{\text {th }}$ DPO. Breast milk was commenced on the $9^{\text {th }}$ DPO. IV fluids and antibiotics were discontinued on the $10^{\text {th }}$ day. By the $14^{\text {th }}$ day, patient had persistent watery diarrhoea and was commenced on Hartman's solution, $35 \mathrm{mls}$ and Oral rehydration Solution (ORS). By the $15^{\text {th }}$ day a clinical diagnosis of dehydration secondary to enteritis was made.

On the $20^{\text {th }}$ day, the baby had developed Jaundice, with a total bilirubin of $15 \mu \mathrm{g} / \mathrm{dl}$ and conjugated bilirubin of $10.4 \mu \mathrm{g} / \mathrm{dl}$. Her packed cell volume (PCV) was $36 \%$. An assessment of neonatal sepsis was made which was treated and she was discharged home on the $29^{\text {th }}$ day on Loperamide (to help slow down bowel motion) and haematemic and seen in the clinic 4 days later with no significant complaints. She attended clinics regularly for 2 months postoperative but was eventually lost to follow up.

\section{Case 2}

A $2.5 \mathrm{Kg}$ male neonate, born to a 22 year old gravida 2, para1 mother, through caesarean section at 34 weeks gestation presented with a history of chills, bilious vomiting and abdominal distension at age 2 days. The mother had a previous history of caesarean section. Antenatal ultrasonography showed that there was polyhydramnious, with multiple distended bowel loops. The baby had an Apgar score of 9 at 1 minute of birth. There was no gross congenital deformity. Erect plain abdominal $x$ - ray revealed paucity of bowel gas in the pelvis with "Triple bubble appearance"and multiple air fluid levels in the left flank, (Fig 2a).

The baby had unconjugated hyperbilirubinaemia. An impression of neonatal intestinal obstruction was made. An IV fluid and broad spectrum antibiotic was set up, with nasogastric intubation. Exploratory laparotomy revealed a dilated duodenum, dilated blind ended proximal jejunum, gangrenous and atretic jejunoileal loops, with the blood supply of the atretic segment appearing in a helical fashion from the ileocolic artery, (Fig 2b).

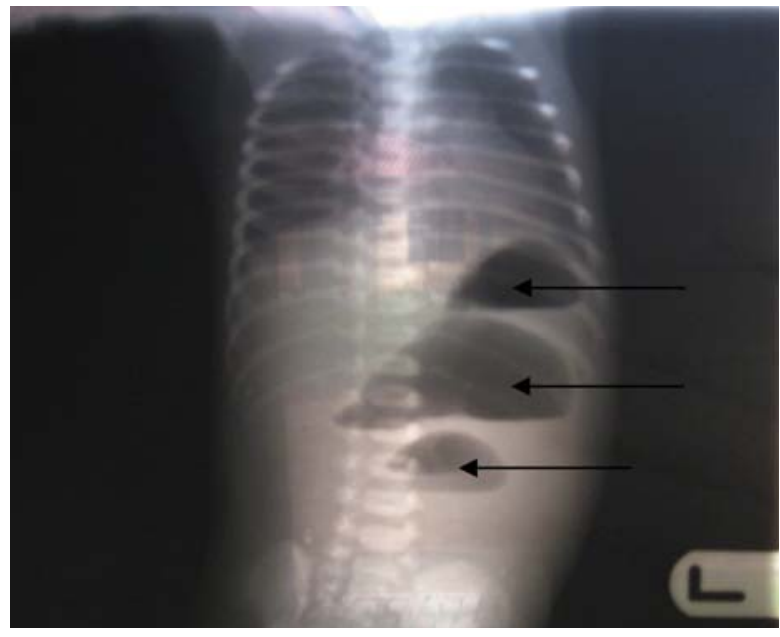

Fig 2a: Erect plain abdominal X-ray showing the triple bubble appearance with multiple fluid levels.

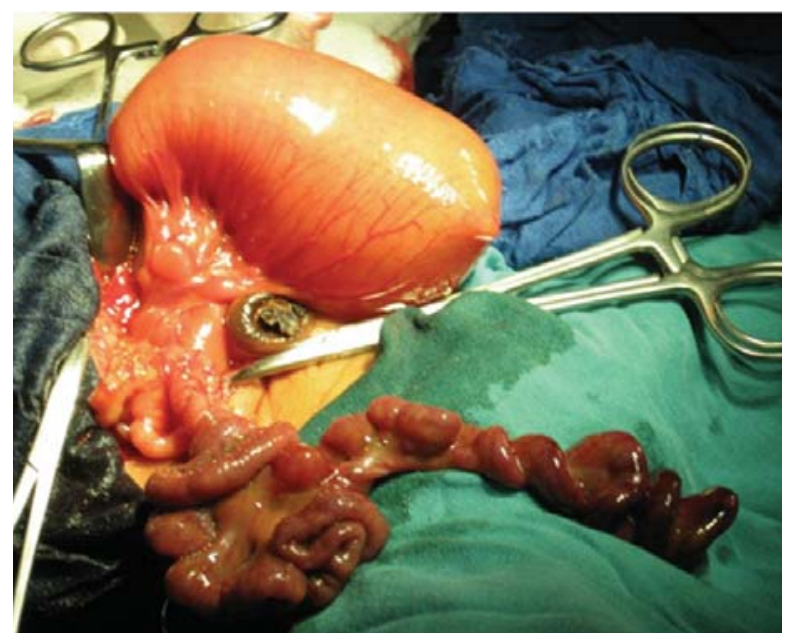

Fig 2b: Surgical finding of a dialated duodenum and proximal jejunum, absent mesentery and atretic and gangrenous ileum. 
The gangrenous portion was excised leaving about $10 \mathrm{~cm}$ of the terminal ileum, $1 \mathrm{~cm}$ of the bulbous atretic proximal jejunum was also excised and an end to side jejunoilealostomy was done to re-establish bowel continuity.

He vomited (coffee colored) on the $10^{\text {th }}$ DPO and developed recurrent abdominal distension, on the $17^{\text {th }}$ DPO (brownish and faeculent) The NG tube was reinserted and a follow up plain abdominal x-ray done showed multiple air fluid levels, paucity of bowel gas in the pelvis but no free air under the diaphragm. A gastrograffin upper gastrointestinal study done on the $19^{\text {th }}$ DPO showed a normal flow of contrast into the large intestine from the stomach. A gastrograffin barium enema was also done on the $21^{\text {st }}$ DPO which showed a hypoplastic rectum, a narrow, rigid sigmoid colon terminating in a blind pouch and the proximal part of the sigmoid, descending, transverse and ascending colon were not visualized. An impression of a sigmoid colon atresia was made. The baby however died on the $21^{\text {st }}$ DPO.

\section{Case 3}

A two day old preterm male baby delivered at 31 weeks gestation, $1.6 \mathrm{Kg}$ was admitted on account of bilious vomiting and abdominal distension with the suspicion of intestinal obstruction from intestinal atresia. There was premature rupture of membrane (PROM) though the delivery was uneventful. A plain abdominal radiograph showed grossly distended bowel loops in the upper abdomen. Exploratory laparotomy revealed absence of small bowel mesentery, dilated duodenum and proximal jejunum with gangrenous and atretic distal jejunum and ileum, (Fig 3).

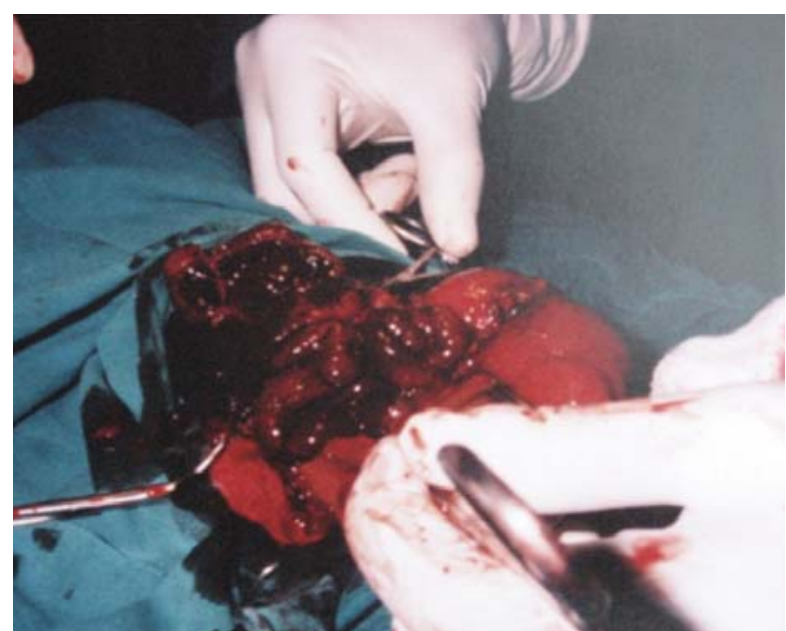

Fig 3: Surgical finding of a dialated duodenum and proximal jejunum, absent mesentery and widespread atretic and gangrenous distal jejunum and ileum.
The superior mesenteric artery was absent and the blood supply was from the ileocolic artery. Thus confirming an Apple peel atretic deformity. The bulbous proximal and atretic portion was excised to about 1.5 $\mathrm{cm}$ in diameter of the bowel taking care to preserve as much proximal bowel as possible. The distal deformity was excised leaving some length of intestine from the ileocaecal junction. An end to side anastomosis was used to re-establish bowel continuity. The procedure was complicated by short gut syndrome because of the massive bowel resection due to widespread gangrene.

\section{Case 4}

A 20 day old male neonate was brought in with a 4 day history of bilious vomiting, passage of greenish stool, abdominal distention and fever. Clinical examination revealed an empty rectum, with a triple bubble appearance on the abdominal radiograph (Figs $4 a)$ and a clinical diagnosis of intestinal obstruction was made.

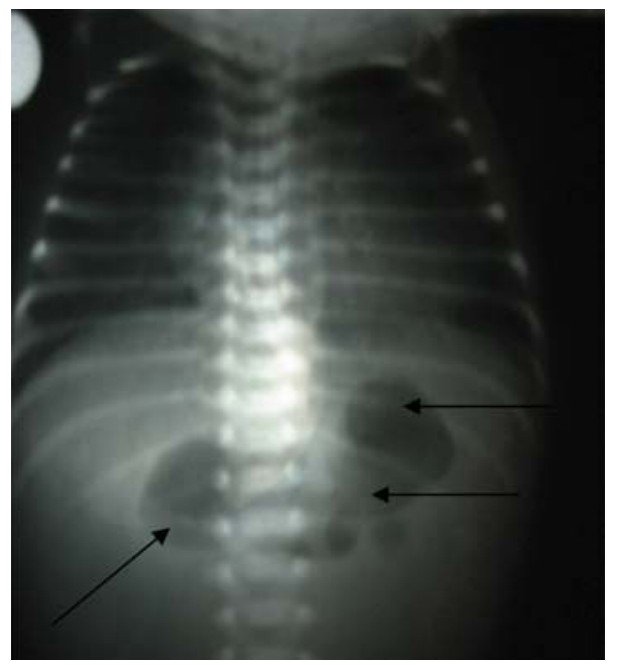

Fig 4a: Supine plain abdominal X-ray showing the triple bubble appearance.

The baby was started on IV fluid and antibiotics (Cefotaxime, Flagyl) and a nasogatric tube were inserted. Exploratory laparotomy revealed blind ended jejunum with no mesentry, (Fig 4b).

Resection of the atretic segment was done with an end to side jejunoileal anastomosis. Baby passed greenish stool after surgery. NG tube was removed 13 day post-operative. He has resumed oral feeding and vomiting has stopped since then. Patient did well although he has lost weight. He however died about two weeks postoperative. 


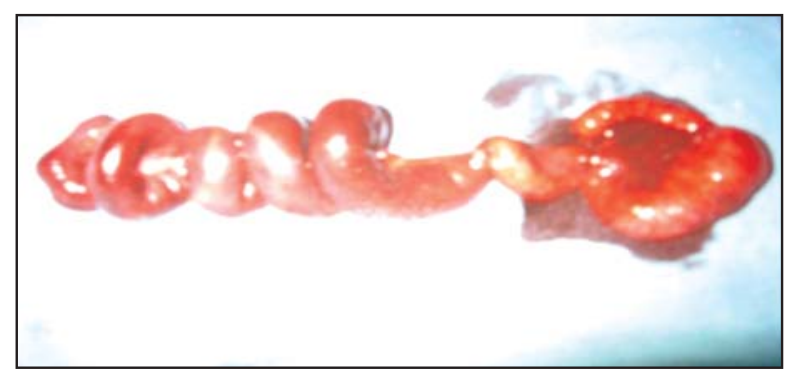

Fig 4b: Surgical finding of a dialated duodenum and proximal jejunum, absent mesentery and atretic ileum winding round the ileocolic artery in a helical fashion.

\section{Results}

Of the four neonates, 3 were males and one was female (Table 1 ) with an age range of 2 days to 20 days, born to young mothers of ages between 22-28 years. None of them had a similar history in the family. Three of them were preterm, delivered at 32-34 weeks gestation, one of whom was delivered through a caesarean section. Cases 1 and 3 had a history of premature rupture of membrane during their pregnancies. The most common presenting symptoms were bilious vomiting, abdominal distension and fever. All of them passed meconium at birth.

Radiologically, all of them had dilated bowel loops proximally, showing more than two air bubbles in the abdomen, thus differentiating them from the "double bubble appearance" of duodenal atresia. The abdominal radiograph also showed paucity of bowel gas in the lower abdomen in all the patients.

Three of the neonates were lost to the complications of surgery, neonatal sepsis and malabsorption syndrome.
Only one of them had associated volvulus, while another had sigmoid colon atresia. Three of the neonates had gangrenous small bowel loops at operation.

\section{Discussion}

The fact that we saw only 4 cases of apple peel atresia in six years confirms the rarity of this disease entity which is corroborated in literature ${ }^{1,10,15,16,17}$. More males were seen in this case series than females, though Shalkow et $\mathrm{al}^{2}$ claim that intestinal atresia generally affects boys and girls equally. Jejunal atresia is said to be autosomal recessive $e^{14,16}$, while Shalkow et $\mathrm{al}^{2}$ claim that the familial type is autosomal dominant.

Intestinal atresia accounts for one third of all cases of neonatal obstruction. In West Africa, it is the 4th most common cause of neonatal intestinal obstruction after anorectal malformations, Hirschsprung disease and strangulated hernia ${ }^{2}$. Jejunoilial atresia is more common than duodenal or colonic atresia ${ }^{2}$. The claim by Louw and Barnard in 1955 that jejunoileal atresia is caused by intrauterine mesenteric vascular accident rather than failure of recanalization of the gastrointestinal tract was corroborated in this study as the superior mesenteric artery was absent in all the neonates and the ileocolic artery was the source of blood supply with the small intestinal loops winding round it in a helical fashion ${ }^{2,17}$. Shalkow et $\mathrm{al}^{2}$,Zerella et $\mathrm{al}^{5}$ and Yuno et $\mathrm{al}^{17}$ also claimed that intrauterine volvulus, incarceration of intestine in the umbilical ring, intussusception, internal hernia, and constriction of the mesentery in a tight gastrochisis or omphalocoele defect were possible causes of a vascular accident with resultant intestinal atresia. Therefore the volvulus in Case 1 in this case series is the most likely cause of its atresia.

Table 1: Showing summary of the four cases seen over six years

\begin{tabular}{|c|c|c|c|c|c|c|c|c|}
\hline Case & Age & Sex & $\begin{array}{c}\text { Gestational } \\
\text { Age at birth }\end{array}$ & $\begin{array}{c}\text { Mode of } \\
\text { Delivery }\end{array}$ & $\begin{array}{c}\text { Weight } \\
\text { at birth }\end{array}$ & Prematurity & Complications & $\begin{array}{c}\text { Operative } \\
\text { Outcome }\end{array}$ \\
\hline 1 & 4 days & Female & 34 weeks & $\begin{array}{c}\text { Spontaneous } \\
\text { Vertex } \\
\text { Delivery }\end{array}$ & $2.4 \mathrm{Kg}$ & Yes & $\begin{array}{c}\text { Diarroea. } \\
\text { Dehydration } \\
\text { Jaundice. } \\
\text { Neonatal } \\
\text { Sepsis. }\end{array}$ & $\begin{array}{c}\text { Did well for at } \\
\text { least } 2 \text { months } \\
\text { postoperative } \\
\text { before he was lost } \\
\text { to follow up }\end{array}$ \\
\hline 2 & 3 days & Male & 34 weeks & $\begin{array}{c}\text { Caesarean } \\
\text { Section }\end{array}$ & $2.5 \mathrm{Kg}$ & Yes & $\begin{array}{c}\text { Persistent } \\
\text { vomiting. } \\
\text { Recurrent } \\
\text { abdominal } \\
\text { distension }\end{array}$ & $\begin{array}{c}\text { Death, } 21 \text { days } \\
\text { postoperative. }\end{array}$ \\
\hline 3 & 2 days & Male & 31 weeks & $\begin{array}{c}\text { Spontaneous } \\
\text { Vertex } \\
\text { Delivery }\end{array}$ & $1.6 \mathrm{Kg}$ & Yes & Diarrhoea & $\begin{array}{c}\text { Death } 2^{\text {nd }} \text { day } \\
\text { Postoperative. }\end{array}$ \\
\hline 4 & 20 days & Male & 37 weeks & $\begin{array}{c}\text { Spontaneous } \\
\text { Vertex } \\
\text { Delivery }\end{array}$ & $2,6 \mathrm{Kg}$ & No & Loss of weight & $\begin{array}{c}\text { Death two weeks } \\
\text { postoperative }\end{array}$ \\
\hline
\end{tabular}


There are five types of intestinal atresia, including,

Type I - Membrane

Type II - Blind ends joined by fibrous cord

Type IIla - Disconnected blind end

Type IIIb - Apple-peel deformity

Type IV - Multiple, string of sausages ${ }^{2,16}$

All the 4 cases in this series was of the type IIIb jejunoileal atresia.

In apple peel atresia, the distal small intestine spirals around its vascular supply and resembles an apple pee ${ }^{10}$, as was confirmed in this study. In intestinal atresia type IIIb (Christmas tree deformity), both intestinal segments are separated and the mesenteric defect is large ${ }^{2,18}$. The proximal atretic segment is in the upper jejunum, near the ligament of Treitz, and the pouch is distended and lacks dorsal mesentery. The superior mesenteric artery distal to the middle colic branch is absent. The collapsed distal intestine helically encircles a small vessel (marginal artery) that arises from the ileocolic or right colic arcades, or the inferior mesenteric artery, and its vascularity may be impaired ${ }^{2}$. These findings were confirmed in the present study and the impairment of the vascular supply is the most likely cause of the gangrenous intestine.

Jejunoileal atresias which could be single, multiple and familial ${ }^{9,10}$, can be identified on the basis of polyhydramnios present during prenatal ultrasonographic evaluation ${ }^{2}$ as was seen in Case 2 in the present study, Shalkow et $a^{2}$ also opined that some patients may not pass meconium in the first day of life and this does not rule out intestinal atresia. All the neonates in this study passed meconium, even the Case 2 who was eventually found to have atresia of the sigmoid colon.

The clinical presentation of patients with jejunoileal atresia include polyhydramnios on prenatal ultrasound (28\%), prematurity (35\%), low birth weight (25-50\%), Bilious emesis that warrants emergent surgical evaluation (most patients), abdominal distention (in distal atresias), jaundice (32\%) and failure to pass meconium in the first 24 hours $^{2}$. Most of these signs were found in the patients presented. Continuous fluid loss manifests as dehydration, which causes sunken fontanel and dry membranes, decreased urine output (best clinical indication of tissue perfusion), tachycardia, decreased pulse pressure, low-grade fever, neurological involvement, manifested by irritability, lethargy, or coma ${ }^{2}$ All the cases presented were febrile thus supporting continuous fluid loss.
Most patients present with bilious emesis, which indicates that the obstruction is distal to the ampulla of Vater ${ }^{2,12}$. One of the three portions of the jejunum twists around the marginal artery of the colon and causes an atresia. Symptoms in this disorder include vomiting, abdominal distension and constipation ${ }^{16,19}$. These were confirmed in the present study. Patients are frequently premature $(35 \%)$. Three of the patients in this study were premature. One third of infants with jejunal atresia, one fourth of those with ileal atresia, and more than one half of those with multiple atresias have low birth weight ${ }^{2}$. About $32 \%$ of infants with jejunal atresia and $20 \%$ of those with ileal atresia have jaundice, which is characteristically due to indirect hyperbilirubinemia ${ }^{2}$ as we seen in Case 2 in the present study. Case 1 also developed postoperative jaundice.

Abdominal distension is most evident in cases of ileal atresias, in which it is diffuse, as opposed to proximal jejunal atresias, in which the upper abdomen is distended and the lower abdomen is scaphoid ${ }^{2}$. This was confirmed in all our patients.

Immediately after delivery, patients are usually relatively healthy but with time, they develop signs of hypovolaemia (sunken eyes, dry skin and mucous membranes) due to vomiting and intra-abdominal third space loss secondary to obstruction ${ }^{2}$. They are usually hungry babies who suck well but cannot tolerate feeds and so continue to vomit profusely, as was seen in our patients.

In a healthy neonate, air can usually be identified in the stomach within minutes of birth, and within 3 hours the entire small bowel usually contains gas. After 8-9 hours, healthy neonates demonstrate sigmoid gas. The diagnosis of obstruction is based on some interruption in this air distribution which can be confirmed on plain radiographs ${ }^{10}$. Delayed passage of gas through the neonatal gut may occur as a result of traumatic delivery, septicemia, hypoglycemia, or brain damage ${ }^{10}$. Absence of gas in the bowel may be noted in neonates with severe respiratory distress who are undergoing mechanical ventilation and in cases of continuous nasogastric suction ${ }^{10}$. All neonates in the present study demonstrated abnormal bowel gas distribution on their radiographs in form of the" triple bubble sign" which can be explained by gas in the distended stomach, duodenum and proximal jeunal (pre-atretic).

Patients with apple peel atresia have a high incidence of prematurity $(70 \%)$, malrotation (54\%), short gut $(74 \%)$, multiple atresia $(15 \%)$, complications $(63 \%)$ 
and mortality (54\%). However mortality has been said to decrease from $63 \%$ to $47 \%$ since $1970^{12,14,19}$, contrary to findings in this study.

Operative management included resection with primary anastomosis in $69 \%$ of all patients and temporary enterostomies in $26 \%{ }^{2}$. Fockens reported the first successful surgical repair of a patient with intestinal atresia but its mortality rate for surgical correction was high for quite some time even in the best paediatric surgical centers ${ }^{2,20}$.

After operative management, $15 \%$ of children had resultant short bowel syndrome. Oral feeding was allowed on median day 7 , and full energy expenditure via the enteric route was reached on median day 20. Forty-seven percent of infants required central venous line placement for total parenteral nutrition. Early postoperative complications occurred in $28 \%$ of patients with jejunoileal atresia and late postoperative complications in $17 \%^{19,21}$. In the present study mortality rate was high as 3 of the neonates were lost to the complications of operation although one of them did well for at least 2 months postoperative and was lost to follow up.

The largest study of neonates with jejunoileal atresia showed that short bowel syndrome seems to be the biggest problem resulting in long hospital stay, more feeding problems and higher mortality and morbidity ${ }^{1,14,19}$. Managing children with short bowel has however improved because of the use of total parentral nutrition (which is not available in our environment), new operative techniques, and better intensive care ${ }^{19}$. These are not readily available in this setting which can thus explain the high mortality rate we had. Though survival has increased in the last 15 years, it has cost the surviving neonates a high percentage of late complications ${ }^{19}$. Patients usually die from short bowel syndrome which can probably explain the deaths we had in this case series and complications related to total parenteral nutrition ${ }^{2}$.

\section{Conclusion}

This study has shown that a simple plain abdominal $\mathrm{X}$-ray is enough to diagnose a jejunoileal atresia and of course apple peel atresia. The triple bubble picture on plain X-ray is highly suggestive of this disease entity. Gangrene was also found to be a common finding in these patients at surgery. In our environment, the complications of surgery are the main cause of the high mortality rate and probably the non-availability of parenteral nutrition.

\section{References}

1. Turnock RR, Brereton RJ, Spitz L, Kiely EM. Primary Anastomosis in Apple-peel Bowel Syndrome. J Paediatr Surg 1991;26(6):718-20.

2. Shalkow J, Reynolds M. Small Intestinal Atresia and Stenosis. Retreived from http://emedicine. medscape.com/article/939258-overview\#showall 2010.

3. Gray SW, Skandalakis JE. Embroyology for Surgeons. Philadelphia, WB Saunders company. 1972. pp. 151

4. Weitzman JJ, Vanderhoof RS. Jejunal atresia with agenesis of the dorsal mesentry with "Christmas Tree Deformity" of the small intestine. Am J Surg 1966;(3):443-49. doi:10.1016/s00029610(66)80024-7.

5. Zerella JT, Martin LW. Jejunal atresia with absent mesntary and a helical ileum. Surgery1976; 80(5):550-553.

6. Zwiren GT, Andrews HG, Ahmann P. Jejunal atresia with agenesis of the dorsal mesentery ("apple peel small bowel"). J Paediatr Surg 1972;7(4):414-19.

7. Blyth H, Dickson JAS. Apple peel syndrome (congenital intestinal atresia). A family study of 7 index patients. J Med Genet 1969;6:275-77.

8. Christmas tree deformity. Redirected from Apple peel atresia. Retrieved from http://medical-dictionay. thefreedictionary.com/Apple+Peel+Syndrome.

9. Farag TI, Teebi AS. Apple peel syndrome in sibs. $J$ Med Genet 1989;26(1):67-68.

10. Berrocal T, Larnas M, Gutierrez J, Torres I, Prieto C, del Hoto ML. Congenital Anomalies of the small intestine, colon, rectum. Radiographics 1999;19:1219-36.

11. Chirdan $L$ B, Uba $A F$ and Pam SD. Intestinal atresia: management problems in a developing country. Pediatr Surg Internatl 2004;20:834-37.

12. Dalla Vechia LK, Grosfeld JL, West KW, Rescorla FJ, Scherer LR, Engum SA. Intestinal Atresia and stenosis. A 25 year experience with 277 cases. Arch Surg 1998;133:490-496.

13. Sathyaprasad CB, Elise Crete, Sarah Bouchard, Prognostic factors in Jejunoileal atresia. Paed Surg Int 2009; doi 10.1007/s00383-009-2422-y. 
14. Seashore JH, Collins FS, Markowitz RI, Seashore MR. Familial apple peel jejunal atresia: surgical, genetic, and radiographic aspects. Pediatrics 1987;80(4):540-4.

15. Waldhausen JH, Sawin RS. Improved long-term outcome for patients with jejunoileal apple peel atresia. J Pediatr Surg 1997;32(9):1307-1309.

16. Tadmouri GO, Tadmouri GO, Ali SA. Centre for Arab Genomics Studies.CTGA database. Jejunal atresia, Apple peel bowel syndrome. WHO International classification of disease, 2005.

17. Yuno S, Yamazaki $Y$ and Yoshida T. An extremely rare variant of congenital Jejunileo-colic Atresia. J Paediatr Surg 1997;32(10):1499-1501 .
18. Ros Mar Z, Diez Pardo JA, Ros Miquel M, Benavent I. Apple peel small bowel. A review of twelve cases. Z Kinderchir Grenzgeb 1980;29(4):313-7.

19. Stollman $\mathrm{TH}$, de Blaauw I, Wijnen $\mathrm{MH}$, van der Staak FH, Rieu PN, Draaisma JM, Wijnen RM. Decreased mortality but increased morbidity in neonates with jejunoileal atresia; a study of 114 cases over a 34year period. J Pediatr Surg 2009;44(1):217-21b.

20. Alonso Sainz F, Borrás C, Martínez de Azcoitia, Simonet Salas JM, Femenía Reus A, Ramos Losada R. Apple Peel syndrome: an uncommon form of intestinal atresia. An Esp Pediatr 1979;12(89):627-30.

21. Sato S, Nishijima E, Muraji T, Tsugawa C, Kimura K. Jejunoileal atresia: a 27-year experience. J Pediatr Surg 1998;33(11):1633-5.

\section{How to cite this article ?}

Akinola RA, Osuoji RI. Apple Peel Small Bowel, a Review of Four Cases: Surgical and Radiographic Aspects. J Nepal Paediatr Soc 2011;31(3):227-234. 